\title{
Severe coronary vasospasm associated with hyperthyroidism causing myocardial infarction
}

\author{
Navroz D Masani, David B Northridge, Roger J C Hall
}

\begin{abstract}
A 48 year old woman presented with angina after an anterior myocardial infarction and was found to be hyperthyroid. Coronary angiography showed a stenosis of the left coronary os and a long, severe stenosis of the left anterior descending artery which was partially relieved by glyceryl trinitrate. Three months later, after radioactive iodine treatment had rendered her euthyroid, repeat coronary angiography showed entirely normal coronary arteries. This unusual case establishes an association between hyperthyroidism and coronary vasospasm resulting in myocardial infarction.
\end{abstract}

(Br Heart F 1995;74:700-701)

Keywords: coronary vasospasm; hyperthyroidism; myocardial infarction

Hyperthyroidism is a rare cause of coronary artery spasm. We present an unusual case in which severe coronary spasm resulting in myocardial infarction was associated with hyperthyroidism.

\section{Case report}

A previously well 48 year old woman, with no risk factors for cardiovascular disease, presented to her local hospital with a 2 day history of severe chest pain and increasing dyspnoea, preceded by a 2 month history of exertional angina and palpitation. On direct questioning she gave a history of resting tremor, heat intolerance, and weight loss of $5 \mathrm{~kg}$. Physical examination showed a blood pressure of $120 / 70 \mathrm{~mm} \mathrm{Hg}$, a regular pulse of 110 /minute, and a prominent apical impulse. A small nodular goitre was palpable and lid lag noted.

Department of Cardiology, University Hospital of Wales, Cardiff

N D Masani

D B Northridge

R J C Hall

Correspondence to: Dr N D Masani, Department of Cardiology, University Hospital of Wales, Heath Park, Cardiff CF4 4XW.

Accepted for publication 17 July 1995
Her electrocardiogram showed a sinus tachycardia, $Q$ waves, and ST elevation in the anterior leads and $T$ wave inversion in the lateral leads suggesting recent anterior myocardial infarction. Short runs of atrial fibrillation were seen. Two days after admission she developed further chest pain associated with ST depression and was transferred to the University Hospital of Wales for further investigation.
Routine biochemical and haematological tests, liver function tests, and serum cholesterol and triglyceride concentrations were normal. Serum thyroid stimulating hormone was undetectable (normal $0.05-4.2 \mathrm{mU} / \mathrm{l}$ ) and free thyroxine was $>100 \mathrm{pmol} / 1$ (normal 12-28) indicating hyperthyroidism. Antithyroid antiobodies were not detectable and a radioactive iodine tyroid scan showed an enlarged gland with increased uptake, compatible with multinodular goitre.

Treatment with carbimazole, slow-release propranolol (160 mg twice a day), isosorbide mononitrate (60 mg once a day), and aspirin (150 mg once a day) was started. Coronary angiography (figure A) showed a significant narrowing of the left main stem and a $1 \mathrm{~cm}$ long, concentric $90 \%$ stenosis in the proximal segment of the left anterior descending artery with delayed distal filling. The right coronary artery was normal. After intra-coronary nitrate was given there was partial resolution of the narrowing in the anterior descending artery, but no resolution of the main stem stenosis. Left ventriculography showed antero-apical akinesia.

Coronary angiography was repeated 3 months later, when she was euthyroid (free thyroxine $28 \mathrm{pmol} / \mathrm{l}$, free triiodothyronine 6.9 $\mathrm{pmol} / \mathrm{l}$ (normal 3.0-9.0) and thyroid stimulating hormone $0.05 \mathrm{mU} / \mathrm{l}$ ) and symptom free. There was complete resolution of all coronary abnormalities (figure B).

\section{Discussion}

Angina occurs in up to $20 \%$ of patients with thyrotoxicosis, usually because of coronary atheroma and increased sympathetic activity. ${ }^{1}$ The cause of ischaemia and infarction in thyrotoxic patients with normal coronary arteries is unclear. It may be due to in situ coronary thrombosis ${ }^{2}$ or to a direct metabolic effect of thyroid horomone on the myocardium $^{3}$ or be secondary to supraventricular tachycardia or atrial fibrillation. ${ }^{4}$ More recently, coronary vasospasm has been described in patients with myocardial ischaemia and hyperthyroidism; $;^{5-9}$ its cause, however, is unknown.

This case is unique because: (a) a close association was established between coronary vasospasm induced by hyperthyroidism and 

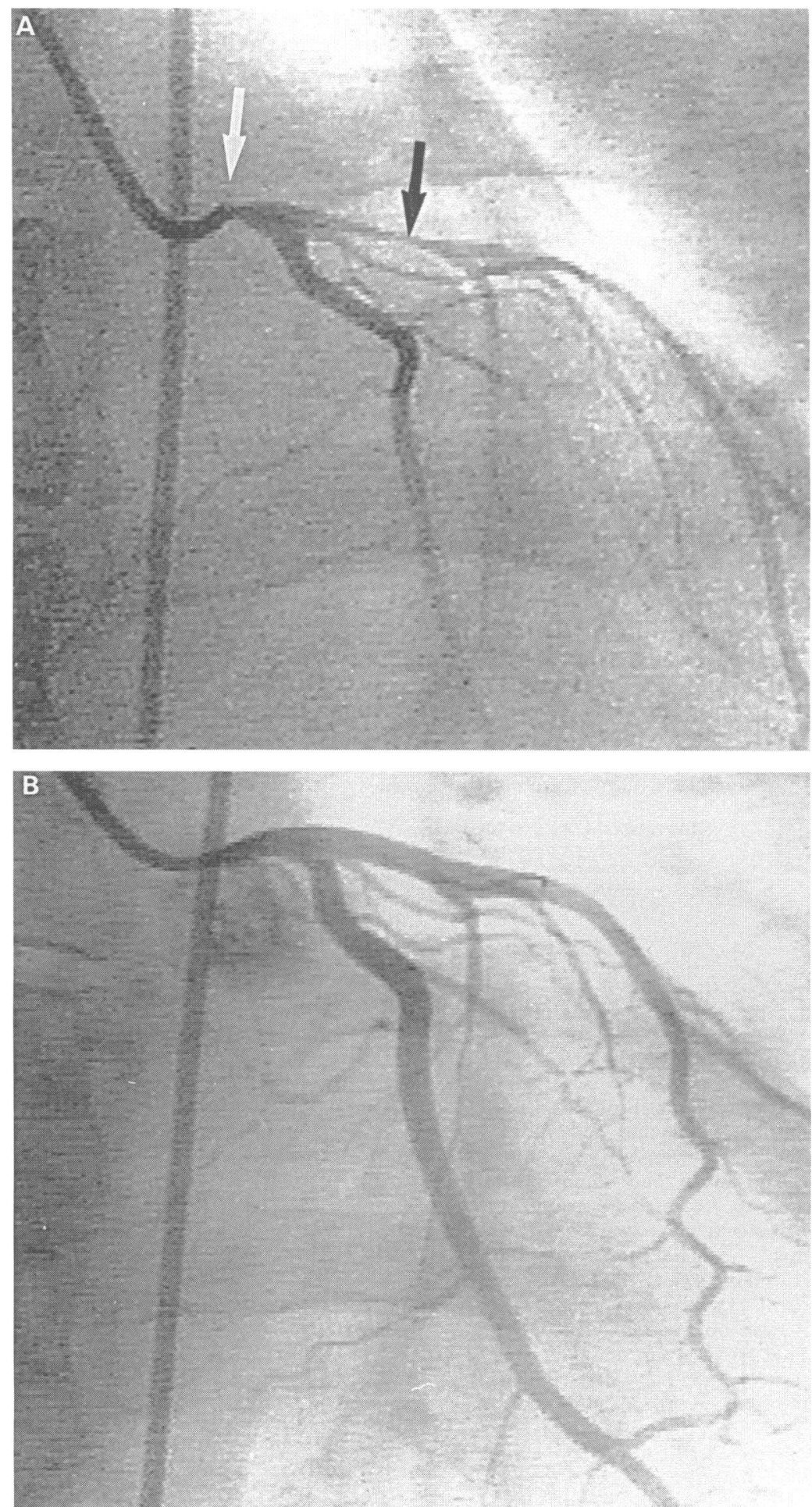

Figure (A) Left coronary angiogram in the right anterior oblique projection (at presentation). A long concentric stenosis of the proximal left anterior descending coronary artery is seen (black arrow) and the left main stem is abnormally narrow at the catheter tip (white arrow). (B) Left coronary angiogram in the right anterior oblique projection ( 3 months later). There is resolution of all abnormalities. The calibre of the entire left coronary artery appears larger. myocardial infarction, $(b)$ severe narrowing of the left coronary os was demonstrated, indicating the potentially serious nature of this condition; and (c) repeat coronary angiograms were normal after the patient had been rendered euthyroid. In common with previous observations $^{16}$ our case was notable for mild clinical manifestations of thyrotoxicosis despite considerable biochemical changes. We conclude that hyperthyroidism should be considered as a cause of life-threatening myocardial ischaemia, particularly in patients without risk factors for atherosclerotic disease.

1 Somerville W, Levine SA. Angina pectoris and thyrotoxicosis. Br Heart $\mathcal{F} 1950 ; 12: 245-7$.

2 Kotler MN, Michaelides M, Bouchard RJ, Warbasse JR. Myocardial infarction associated with thyrotoxicosis. Arch Intern Med 1973;132:723-8.

3 Resnekov L, Falicov RE. Thyrotoxicosis and lactateroducing angina pectoris with normal coronary arteries. Br Heart f 1977;39:1051-7.

4 Gordon JA, Lenkei SC. Thyrotoxicosis associated with myocardial infarction. Can Med Assoc f 1964;90:1128-9.

5 Moliterno D, DeBold CR, Robertson RM. Case report: Coronary vasospasm-relation to the hyperthyroid state. Am f Med Sci 1992;304:38-42.

6 Wei JY, Genecin A, Greene HL, Achuff SC. Coronary spasm with ventricular fibrillation during thyrotoxicosis: response to attaining euthyroid state. Am f Cardiol 1979; 43:335-9.

7 Featherstone HJ, Stewart DK. Angina in thyrotoxicosis: thyroid-related coronary artery spasm. Arch Intern Med 1983;143:554-5.

8 Nakano T, Konishi T, Takezawa $H$. Vasospastic angina in thyrotoxicosis-case reports. Angiology 1987;38: 717-22.

9 Papazoglou N, Kelermenos N, Andriopoulos J, Prionas D. asospastic angina with hyperthyroidism. Heart and Lung 1987;16:437-8. 